\title{
Estimating of student success with artificial neural networks
}

Raziye Demiralay a *,

Ibrahim Akdenizli b,

Halime Boztoprak c,

Suggested Citation:

Abstract 
1. Introduction 
2. Method

2.1. Participant group 
2.2. Data collection tool

2.3. Research model

2.4. Data analysis

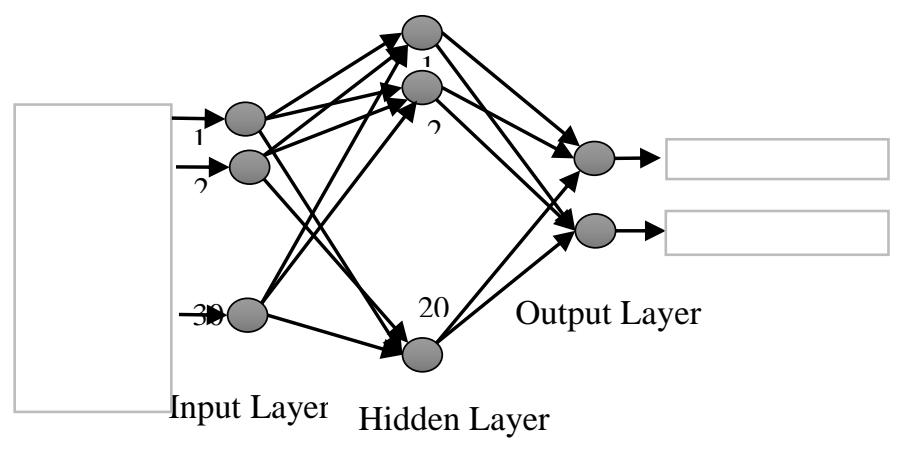

Figure 1. Multilayered artificial neural network 


\section{Results}

Table 1. Correct Classification Success of Artificial Neural Network Model

\begin{tabular}{|c|c|c|c|c|}
\hline ANN & Status & Target & Output & $\begin{array}{c}\text { Correct } \\
\text { Classification }\end{array}$ \\
\hline
\end{tabular}

4. Discussion and Conclusion 


\section{References}


$\longrightarrow$ 